SUBJECT AREAS:

CHEMISTRY

NUCLEAR PHYSICS

Received

22 May 2014

Accepted

2 October 2014

Published

21 October 2014

Correspondence and requests for materials should be addressed to S.E.L. (lapis@mir.wustl.

\section{Feasibility of Isotope Harvesting at a Projectile Fragmentation Facility: ${ }^{67} \mathrm{Cu}$}

\author{
Tara Mastren' , Aranh Pen², Graham F. Peaslee ${ }^{2}$, Nick Wozniak², Shaun Loveless³ , Scott Essenmacher², \\ Lee G. Sobotka' ${ }^{1}$, David J. Morrissey ${ }^{4} \&$ Suzanne E. Lapi ${ }^{1,3}$
}

\begin{abstract}
'Department of Chemistry, Washington University, St. Louis, MO, 631 10, ${ }^{2}$ Department of Chemistry, Hope College, Holland, MI 49423, ${ }^{3}$ Department of Radiology, Washington University, St. Louis, MO, 631 10, ${ }^{4}$ Department of Chemistry, Michigan State University, E. Lansing, Ml 48824.
\end{abstract}

The work presented here describes a proof-of-principle experiment for the chemical extraction of ${ }^{67} \mathrm{Cu}$ from an aqueous beam stop at the National Superconducting Cyclotron Laboratory (NSCL). A $76 \mathrm{MeV} / \mathrm{A}^{67} \mathrm{Cu}$ beam was stopped in water, successfully isolated from the aqueous solution through a series of chemical separations involving a chelating disk and anion exchange chromatography, then bound to

NOTA-conjugated Herceptin antibodies, and the bound activity was validated using instant thin-layer chromatography (ITLC). The chemical extraction efficiency was found to be $88 \pm 3 \%$ and the radiochemical yield was $\geq 95 \%$. These results show that extraction of radioisotopes from an aqueous projectile-fragment beam dump is a feasible method for obtaining radiochemically pure isotopes.

T here are many isotopes that could be useful in a range of disciplines from medicine to stockpile stewardship, geology, nuclear astrophysics and biology that are not available in the quantities needed from conventional production methods based on small medical cyclotrons or reactors ${ }^{1-7}$. The construction of the Facility for Rare Isotope Beams (FRIB) will allow "harvesting" usable quantities of many of these isotopes, concurrent with secondary-beam operations for basic nuclear science experiments. The FRIB design has provisions for delivering research quantities ( $\mu \mathrm{Ci}$ to $\mathrm{Ci}$ ) of radioisotopes as an ancillary service to the on-line experimental program by collecting radioisotopes produced or stopped in an aqueous beam dump ${ }^{8,9}$ in the primary target facility while secondary beams are produced for on-line experiments. Ideally this collection or "harvesting" of isotopes at FRIB could provide isotopic material for which there is currently no comparable source.

One such radioisotope is ${ }^{67} \mathrm{Cu}$ which can be used in medicine as a therapeutic isotope ${ }^{6,10,11}$. Its relatively long 2.58 day half-life is ideal for labeling antibodies that also have several-day biological half-lives. Obtaining therapeutic doses that are typically on the order of hundreds of $\mathrm{mCi} /$ patien $\mathrm{t}^{12}$ has proved to be quite difficult due to inconsistent production and no reliable continuous supply $y^{6,12-14} \cdot{ }^{67} \mathrm{Cu}$ can be made via several nuclear reactions: ${ }^{68} \mathrm{Zn}(\mathrm{p}, 2 \mathrm{p}){ }^{67} \mathrm{Cu},{ }^{70} \mathrm{Zn}(\mathrm{p}, \alpha){ }^{67} \mathrm{Cu},{ }^{67} \mathrm{Zn}(\mathrm{n}, \mathrm{p}){ }^{67} \mathrm{Cu}$, and ${ }^{68} \mathrm{Zn}(\gamma, \mathrm{p}){ }^{67} \mathrm{Cu}$; however each reaction has practical drawbacks. For example, ${ }^{68} \mathrm{Zn}(\mathrm{p}, 2 \mathrm{p}){ }^{67} \mathrm{Cu}$ has a low but broad (in energy) cross section and in order to efficiently produce the large quantities needed for therapeutic doses thick targets and high-energy proton accelerators such as those at Brookhaven ${ }^{15,16}$ or Los Alamos National Laboratories ${ }^{17}$ need to be employed. These are multiuser facilities that cannot routinely dedicate proton beam to produce a continuous supply of ${ }^{67} \mathrm{Cu}^{12}$. Studies at several facilities of the ${ }^{70} \mathrm{Zn}(\mathrm{p}, \alpha)^{67} \mathrm{Cu}$ reaction have obtained varying yields and the production of the large quantities needed for therapeutic studies are challenging with this method ${ }^{18-20}$. Production via the ${ }^{67} \mathrm{Zn}(\mathrm{n}, \mathrm{p})^{67} \mathrm{Cu}$ and ${ }^{68} \mathrm{Zn}(\gamma, \mathrm{p}){ }^{67} \mathrm{Cu}$ reactions have undesirable side reactions and concerns about waste products create challenges for their large scale use ${ }^{12}$. It is estimated that FRIB will be able to produce a saturated activity of ${ }^{67} \mathrm{Cu}$ as high as $\sim 2$ Ci depending on the primary beam ${ }^{21}$ so that weekly harvesting of ${ }^{67} \mathrm{Cu}$ could provide a more consistent supply of this isotope. Therefore, given the difficulty of other production methods, the favorable half-life and wellunderstood chemistry of ${ }^{67} \mathrm{Cu}$, this isotope was selected for a proof-of-principle test of isotope harvesting from an aqueous beam stop for projectile fragments. The work reported here can be extended to other projectile fragments collected in an aqueous beam stop.

Previously, a liquid-water target system/beam stop was designed and tested at the NSCL for a first attempt to harvest useful radioisotopes from a beam dump similar to what will exist at FRIB $^{22}$. This system was used successfully to collect several samples of ${ }^{24} \mathrm{Na}$ from a projectile fragment beam at $\sim 85 \mathrm{MeV} / \mathrm{u}$ and an intensity of $\sim 2 \times 10^{6} \mathrm{pps}$. In the present work, the liquid water target system described in ref [8] was used to collect several samples of ${ }^{67} \mathrm{Cu}$ that were also produced as a secondary beam at the NSCL. The aqueous samples were then 
transported to Washington University in St Louis, MO and Hope College in Holland, MI for chemical separation, antibody labeling, and offline counting. We report here the results of these studies and the observation of relatively high chemical extraction efficiency.

\section{Results}

Beam Calibration and Collection. A $76 \mathrm{MeV} / \mathrm{A}{ }^{67} \mathrm{Cu}$ secondary beam of $77 \%$ purity was selected from a fragmented ${ }^{76} \mathrm{Ge}$ primary beam using the A1900 fragment separator ${ }^{22}$ and delivered to the S1 vault where the liquid water target station was set up to collect the incoming beam. In order to quantify the amount of ${ }^{67} \mathrm{Cu}$ delivered to the target, calibration curves had to be developed to convert the signals from the non-intercepting beam monitors that were continuously operating during beam collections and the fullyintercepting Faraday-cups or scintillators that could not be in place during the sample collections.

Two separate calibration methods were used to determine the number of beam particles delivered to the liquid water target station during two calibration runs performed approximately 12 hours apart. One calibration run was prior to most of the collections and the other was post most of the collections. In the first method a calibration curve was established to normalize the proportional data from the non-intercepting beam monitors (Monitors A and B in Figure 1) to the direct measurements of the primary beam current (in $\mathrm{nA}$ ) with a Faraday cup. The proportional rates from A and B were integrated over the course of each run and then multiplied by
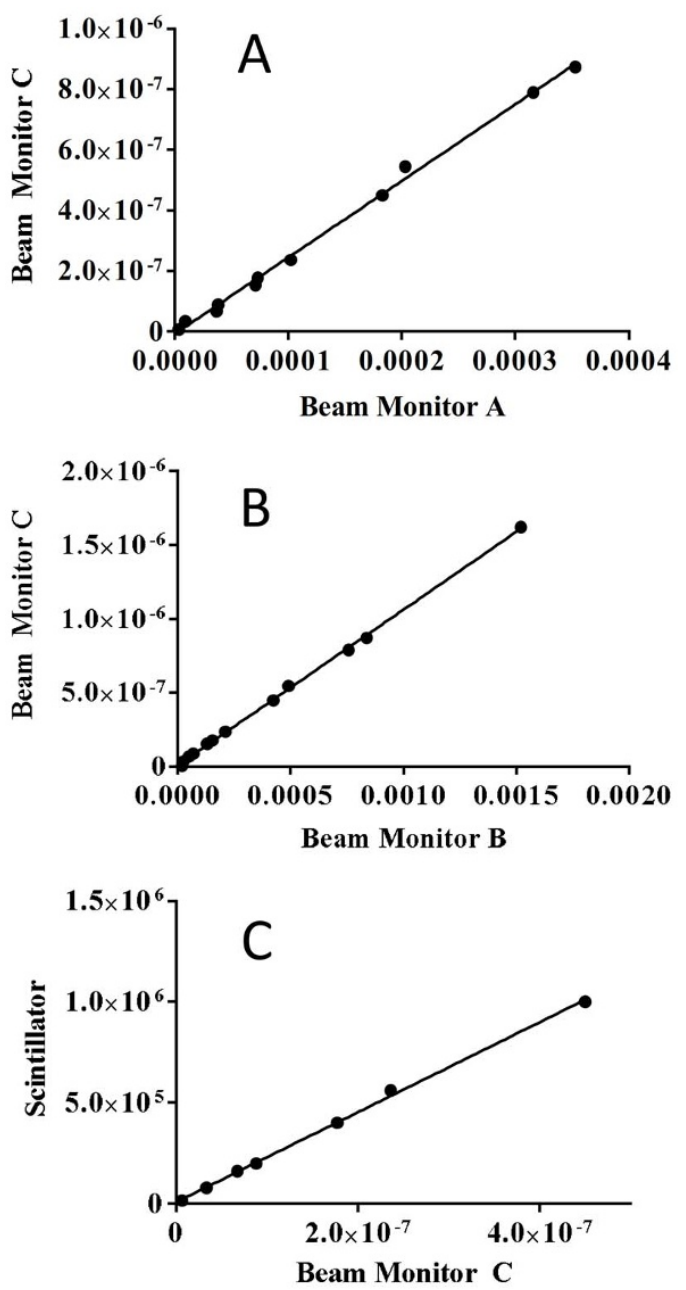

the conversion factor of $4.1 \pm 0.2 \times 10^{5}{ }^{67} \mathrm{Cu}$ ions per second per particle-nA of primary beam (determined by the A1900 operations group) to give the rate of ${ }^{67} \mathrm{Cu}$ atoms delivered. The second method established calibration curves of two non-intercepting beam monitors $A$ and $B$ with the focal-plane plastic scintillator that was used to measure the rate of secondary beam arriving at the A1900 focal plane in particles per second, and these values were integrated over the course of each run and multiplied by the purity factor of $77 \%$ to obtain the total atoms of ${ }^{67} \mathrm{Cu}$ delivered to the beam stop. Due to the different working ranges of the detectors used to measure the beam current, two separate calibration curves had to be used. The first curve converted the high-intensity beam measured with the non-intercepting beam monitors $\mathrm{A}$ and $\mathrm{B}$ to a medium intensity non-intercepting beam monitor $\mathrm{C}$ and the second curve converted the medium intensity non-intercepting beam monitor $\mathrm{C}$ to the low intensity focal-plane scintillator values in particles per second. The data for both methods for the second calibration run carried out post-collection are shown in Figure 1. Linear functions were found to provide excellent descriptions of all of the data.

Five collections were performed, each lasting approximately four hours, and the water from each run was collected as an individual sample for each run. The numbers of ${ }^{67} \mathrm{Cu}$ ions delivered to the liquid water target system in each run, calculated using the two methods, along with the values obtained by measuring the gamma-ray activity for aliquots taken from the samples using an HPGe detector are listed in Table 1. The values obtained from the two calibration curves were
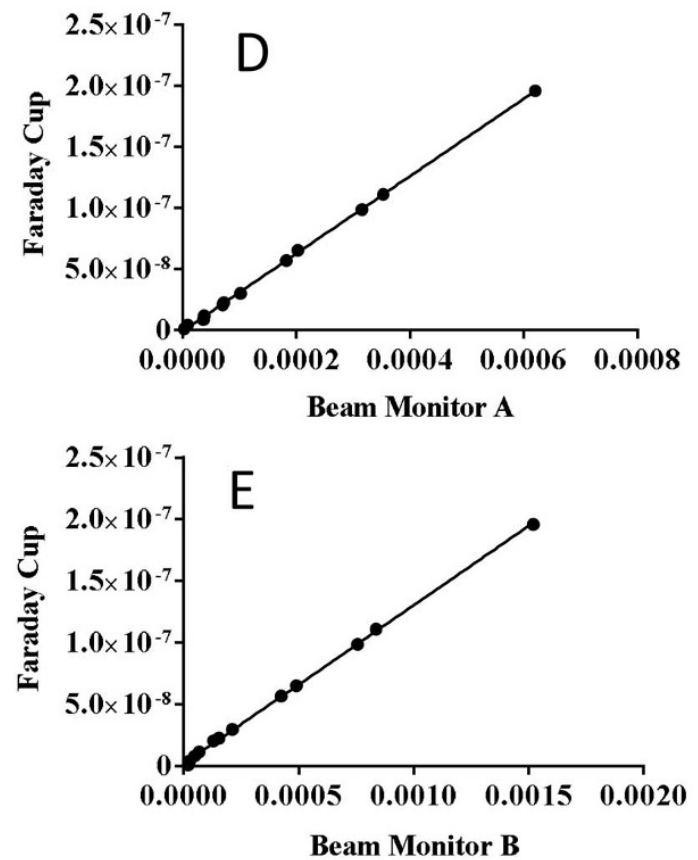

Figure 1 The results of the calibration performed with Method 2 are shown in panels: (A) Beam Monitor A vs Beam Monitor C, (B) Beam Monitor B vs Beam Monitor C, and (C) Beam Monitor C vs Scintillator. The results of the calibration performed with Method 1 are shown in panels:

(D) Beam Monitor A vs Faraday-Cup and (E) Beam Monitor B vs Faraday-Cup. 
Table 1 | Beam delivered to the liquid water target station calculated using beam monitor $A$ or $B$ averaging the data from the prior and post collection calibration curves compared to the amount measured in the water using an HPGe detector

\begin{tabular}{|c|c|c|c|c|c|}
\hline Method & Run $1(\mathrm{kBq})$ & Run $2(\mathrm{kBq})$ & Run 3(kBq) & Run $4(\mathrm{kBq})$ & Run $5(\mathrm{kBq})$ \\
\hline $1 \mathrm{~A}$ & $552(31)$ & $551(31)$ & $521(30)$ & $512(29)$ & $524(30)$ \\
\hline $1 \mathrm{~B}$ & 527 (31) & $527(31)$ & 503 (29) & 493 (28) & 500 (29) \\
\hline $2 \mathrm{~A}$ & $524(24)$ & $523(24)$ & 494 (22) & 485 (22) & 497 (23) \\
\hline Average & $526(29)$ & $525(29)$ & 499 (27) & $490(27)$ & $499(28)$ \\
\hline HPGe & $460(9)$ & $452(9)$ & 425 (8) & $403(8)$ & 397 (8) \\
\hline Transport efficiency & 87 (5) & $86(5)$ & 85 (5) & $82(5)$ & $80(4)$ \\
\hline
\end{tabular}

averaged for beam monitor A and B in both methods. The average transport efficiency of the ${ }^{67} \mathrm{Cu}$ secondary beam into the liquid water target system from the A1900 separator to the water target system was found to be $84 \pm 5 \%$. The modest intensity reduction occurred between the focal plane and the end station or on the collimator immediately in front of the liquid water target station entrance window.

Chemistry. To plan the chemical separation procedure, modeling of the radioisotopes delivered to the water cell and their decay products was carried out using the LISE ++ code with the EPAX3 cross sections and the Nucleonica ${ }^{\odot}$ decay engine, respectively, as was done for the previous ${ }^{24} \mathrm{Na}$ work ${ }^{8}$. The theoretical beam components with half-lives greater than one minute predicted by the LISE + + code to enter the target water are given in Table 2. Note that the projectile fragment separator tends to deliver more isotonic than isotopic contaminants and the primary beam is completely removed.

All of the different metals were effectively separated from the ${ }^{67} \mathrm{Cu}$ collections using the methods described below. The chemical separation relied on absorption to a metal-chelation disk, elution, and separation by anion-exchange chromatography. All methods were validated prior to the ${ }^{67} \mathrm{Cu}$ separations using either non-radioactive species or radioactive surrogate species as tracers. An experiment measuring the efficiency of removing germanium (primary beam) contamination that would be present in the primary beam dump in future work at FRIB was determined using PIXE (Particle Induced Xray Emission) analysis of 0.04-0.5 ppm germanium that was passed through the chelating disk. The results showed average germanium retention of only $2.7 \pm 0.9 \%$ but demonstrated that a small amount germanium binds to the chelating disk. In order to test the separation strategy for copper and gallium, ${ }^{68} \mathrm{Ga}\left(\mathrm{t}_{1 / 2}=68 \mathrm{~min}\right)$ obtained from a ${ }^{68} \mathrm{Ge} /{ }^{68} \mathrm{Ga}$ generator (Eckert and Ziegler, Germany) and ${ }^{64} \mathrm{Cu}\left(\mathrm{t}_{1 / 2}=\right.$ $12.1 \mathrm{~h}$ ) produced at Washington University in St. Louis ${ }^{23}$ were used as radioactive tracers. Passage of ${ }^{68} \mathrm{Ga}$ and ${ }^{64} \mathrm{Cu}$ solutions through the chelation disk found that both metals remained bound within the disk with greater than $99 \%$ efficiency; however, $10 \mathrm{~mL}$ of $6 \mathrm{M} \mathrm{HCl}$ was able to elute, $98 \pm 1 \%$ of ${ }^{64} \mathrm{Cu}$ from the disk, while $97 \pm 2 \%$ of ${ }^{68} \mathrm{Ga}$ remained fixed to the disk. Subsequent separation of copper from zinc and nickel was obtained using anion-exchange chromatography and verified by ion chromatography ${ }^{24}$. The percent of the initial nickel and zinc concentrations were found to be $4 \pm 2 \%$ and

Table 2 | Predicted secondary beam components with half-lives greater than one minute

\begin{tabular}{lll} 
Nuclide & Half-life & \multicolumn{1}{c}{ Particles $/ \mathrm{s}$} \\
\hline${ }^{67} \mathrm{Cu}$ & $2.58 \mathrm{~d}$ & $7.33 \mathrm{E} 6(79.3 \%)$ \\
${ }^{60} \mathrm{Ni}$ & $2.28 \mathrm{~d}$ & $2.93 \mathrm{E} 5(3.2 \%)$ \\
${ }^{65} \mathrm{Ni}$ & $2.52 \mathrm{~h}$ & $1.42 \mathrm{E} 5(1.5 \%)$ \\
${ }^{69} \mathrm{Zn}$ & $56 \mathrm{~m}$ & $1.25 \mathrm{E} 6(13.5 \%)$ \\
${ }^{70} \mathrm{Ga}$ & $21.14 \mathrm{~m}$ & $1.01 \mathrm{E} 3(0.1 \%)$ \\
${ }^{68} \mathrm{Zn}$ & Stable & $2.30 \mathrm{E} 5(2.5 \%)$ \\
\hline
\end{tabular}

$6 \pm 4 \%$, respectively in the $0.5 \mathrm{M} \mathrm{HCl}$ fraction. The average copper recovery from this method was shown to be $86 \pm 4 \%$. The resulting separation process is shown schematically in Figure 2.

Four of the ${ }^{67} \mathrm{Cu}$ samples were shipped to Washington University in St. Louis and processed as described below. Table 3 contains the values for the recovery of ${ }^{67} \mathrm{Cu}$ from the aqueous solutions containing the projectile fragments from the NSCL. The average recovery of ${ }^{67} \mathrm{Cu}$ was found to be $88 \pm 3 \%$, a value in excellent agreement with the tracer studies. The separated (final) ${ }^{67} \mathrm{Cu}$ fractions were analyzed using an HPGe detector (Canberra, USA) calibrated using a $2 \mathrm{~mL}$ mixed source (Eckert and Ziegler, Germany) and no radioactive impurities were observed. The gallium species had completely decayed from the sample before processing due to its short half-life and the decontamination factors for nickel and zinc were 20 and 12.5 respectively.

Test labeling of an antibody, Trastuzumab, was performed to demonstrate that ${ }^{67} \mathrm{Cu}$ separated from the water beam dump would be chemically active. Bicinchoninic acid (BCA) assay showed the final concentration of the conjugated NOTA-Bz-NCS-Trastuzumab to be $7.9 \mathrm{mg} / \mathrm{mL}$. The radiochemical yield of ${ }^{67} \mathrm{Cu}-\mathrm{NOTA}$ Bz-NCS-Trastuzumab of $0.5 \mu \mathrm{Ci} / \mathrm{ug}$ was found to be greater than $95 \%$ by radio instant thin-layer chromatography (ITLC). Figure 3 shows the results of fast-protein liquid chromatography of NOTA-Bz-NCS-Trastuzumab, radio ITLC of ${ }^{67} \mathrm{Cu}$-NOTA-Bz-NCSTrastuzumab, radio ITLC of ${ }^{67} \mathrm{Cu}$-EDTA along with an illustration of the NOTA chelate bound to Trastuzumab.

The production of ${ }^{7} \mathrm{Be}$ from reactions of beam on water. One concern with using an aqueous beam dump to collect high-energy fragments is the buildup of long-lived radioactivity from nuclear reactions with the water. ${ }^{7} \mathrm{Be}\left(\mathrm{t}_{1 / 2}=53.3 \mathrm{~d}\right)$ is produced in reactions between essentially all fast ion beams and water. While ${ }^{7} \mathrm{Be}$ can be easily separated from the ${ }^{67} \mathrm{Cu}$ in this experiment, there may be instances where this contaminant could interfere with the harvesting process. The predicted production rate of ${ }^{7} \mathrm{Be}$ with an incident medium mass beam $(\mathrm{A} \approx 67)$ is $6.4 \times 10^{-4} /$ incident ion $^{21}$. The ${ }^{7} \mathrm{Be}$ concentrations in the present samples were measured using HPGe spectroscopy and showed that the production of ${ }^{7} \mathrm{Be}$ per incident ion on water was $5 \pm 2 \times 10^{-4}$

In addition to ${ }^{7} \mathrm{Be},{ }^{11} \mathrm{C}$ and ${ }^{13} \mathrm{~N}$ were observed byproducts of the interaction of the secondary beam on water. Due to the short half-life of these isotopes they were not observed on the HPGe detector, however their decay was observed using a CsF detector that monitored the collection vials upon completion of a four-hour collection. Future experiments will be designed in order to quantify the amount of these short-lived byproducts that are produced.

\section{Discussion}

A liquid water target station previously designed to collect fast, secondary beams from the National Superconducting Cyclotron Laboratory was used to collect five samples of ${ }^{67} \mathrm{Cu}$. The five collections lasted for four hours each, and the samples were then shipped to Hope College and Washington University in St. Louis for further 


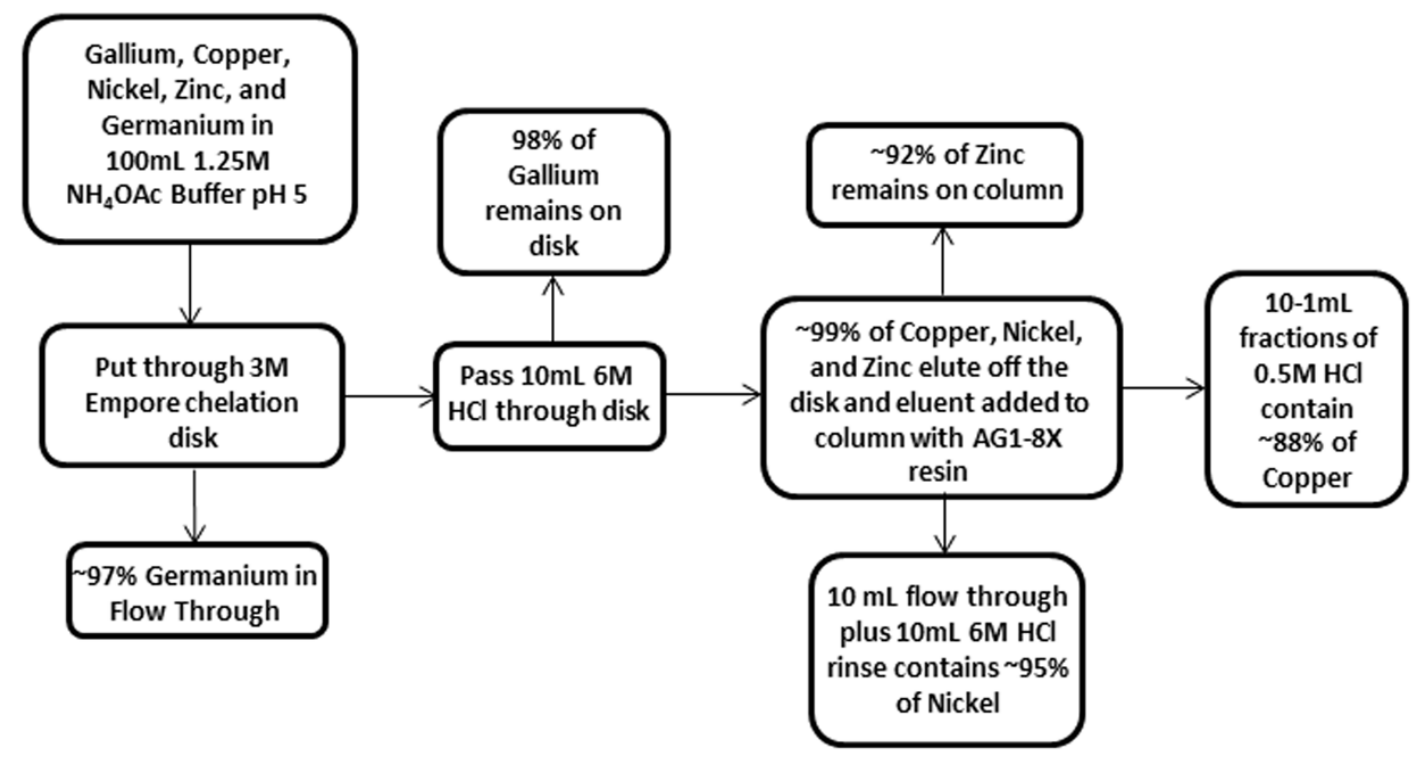

Figure $2 \mid$ Flow chart indicating the separation strategy to recover ${ }^{67} \mathrm{Cu}$ from the aqueous samples containing ${ }^{67} \mathrm{Cu}$ projectile fragments collected at the NSCL.

analysis and chemical separation. ${ }^{67} \mathrm{Cu}$ was effectively separated from the beam contaminants with an average recovery of $88 \pm 3 \%$. The resulting ${ }^{67} \mathrm{Cu}$ was then bound to NOTA-Bz-NCS-Trastuzumab with a radiochemical yield of $>95 \%$. These results demonstrate the feasibility of harvesting useful radioisotopes from the aqueous beam dump at the Facility for Rare Isotope Beams (FRIB) now under construction at Michigan State University. Future experiments will be performed to collect and separate ${ }^{67} \mathrm{Cu}$ from an unanalyzed, i.e., mixed secondary beam to better mimic the conditions that would be present in the actual FRIB beam dump.

The overall production of ${ }^{67} \mathrm{Cu}$ at the NSCL was estimated to be $7.33 \times 10^{6} \mathrm{pps}$ for the ${ }^{76} \mathrm{Ge}$ beam and experimental conditions reported here ${ }^{22}$. An observed rate of $1.13 \times 10^{7}$ pps of ${ }^{67} \mathrm{Cu}$ was measured during this experiment which closely matches the predicted yield for the NSCL. Since the same codes are used to estimate yields at FRIB, this bodes well for an expected production rate of $\sim 2 \mathrm{Ci}$ of ${ }^{67} \mathrm{Cu}$ in the primary beam dump at saturation during regular operations. Similarly the production of ${ }^{7} \mathrm{Be}$ was also measured to be $5.7 \times 10^{3} \mathrm{pps}$, which also compare favorably with the predicted production rate of $4.7 \times 10^{3}$ pps.

While this proof-of-principle experiment made use of a water target cell to collect the beam in a small volume of non-circulating water, in the future at the Facility for Rare Isotope Beams there will be ion exchangers present which could act as potential sources for isotope harvesting. Additional research will be needed in order to determine how much ${ }^{67} \mathrm{Cu}$ (and other isotopes of interest) can be extracted from the resin for the purposes of isotope harvesting.

The most promising radionuclides for isotope harvesting from FRIB would be those which cannot be produced easily by other means, such as with a reactor or small medical cyclotron. Additionally, isotope availability may depend on the needs of the primary user, how pure the isotopes need to be and the frequency

Table 3 | Chemical recovery of ${ }^{67} \mathrm{Cu}$ from the aqueous solutions produced at the NSCL

\begin{tabular}{|lrrr|} 
& Run2(kBq) & Run3(kBq) & Run4(kBq) \\
\hline Starting Activity & $452(9)$ & $425(8)$ & $403(8)$ \\
Recovered Activity & $388(8)$ & $380(8)$ & $353(7)$ \\
Percent Recovery & $86(2)$ & $89(3)$ & $88(2)$ \\
\hline
\end{tabular}

of production. While this is a very promising source of isotopes for many fields, it should be noted that isotopes obtained in this manner will likely be available sporadically. Thus, due to the nature of this technique, it is likely that medium- to long-lived research isotopes will be the most promising targets for isotope harvesting from heavyion fragmentation facilities.

\section{Methods}

Beam Collection and Calibration. A 25 particle-nA $130 \mathrm{MeV} / \mathrm{u}{ }^{76} \mathrm{Ge}$ beam was fragmented using a $510.8 \mathrm{mg} / \mathrm{cm}^{2}$ thick beryllium production target in the A1900 projectile-fragment separator ${ }^{22}$. After fragmentation of the primary beam, ${ }^{67} \mathrm{Cu}$ was selected using the A1900 with a $236.7 \mathrm{mg} / \mathrm{cm}^{2}$ aluminum wedge in the center, the focal plane (FP) mass-selection aperture set to $10 \mathrm{~mm}$, and the momentum acceptance slits open to $2 \%$ (full momentum acceptance). Table 4 lists the exact experimental parameters used in the separator and beam line. The beam intensity and purity were measured using the standard delta-E/Time-of-Flight technique with a silicon-PIN diode in the A1900 focal plane and cyclotron RF signal prior to delivery of the beam to the experimental end station ${ }^{22}$. The secondary beam was collected for four hours in the liquid water target system before being transferred to a collection vessel. Four additional collections each lasting four hours were made before shipping samples to Washington University and Hope College for chemical separation and analysis.

At the NSCL there are several non-intercepting beam monitors, Faraday cups, and a BC-400 plastic scintillator that can be used to measure beam current. The Faraday cups and scintillator can be used to determine particles per second, however, only the non-intercepting beam monitors can be used to measure the beam at full intensity during the sample collections. Calibration curves had to be established comparing the non-intercepting beam monitors with the Faraday cups and scintillators in order to calculate particles per second delivered to the water target station. Two calibrations of the beam monitors were performed during which the beam was attenuated by $10^{-1}$ to $10^{-3}$ times the full beam intensity. The currents from Faraday-cups, non-intercepting beam monitors, and the count rates from the scintillators were recorded and used to construct linear calibration curves. An aliquot from each of the five water samples was analyzed with an HPGe detector to determine the amount of ${ }^{67} \mathrm{Cu}$ present in the sample and decay corrected to the end-of-bombardment in order to determine the beam transport efficiency.

Separations Involving Chelating Disk. All separations using the high-performance extraction disk (3 M Empore, MN) were carried out with $100 \mathrm{~mL} 1.25 \mathrm{M}$ ammonium acetate (trace metals grade) and $\mathrm{pH}$ adjusted to 5 by adding acetic acid (trace metals grade). The solution was then drawn through a $25 \mathrm{~mm}$ diameter extraction disk in a glass microanalysis vacuum filter holder (Millipore, MA) with vacuum after the disk was pretreated by rinsing with $20 \mathrm{~mL}$ milli-Q water, $20 \mathrm{~mL} 3 \mathrm{M}$ nitric acid (trace metals grade), 2-50 mL milli-Q water, $50 \mathrm{~mL} 0.1 \mathrm{M}$ ammonium acetate, followed by two additional rinses of $25 \mathrm{~mL}$ milli-Q water, allowing the disk to dry between each rinse. When passing the $100 \mathrm{~mL}$ sample through the extraction disk a new vacuum flask was used to save the eluent so that it could be analyzed by HPGe detector for radioactivity that did not bind to the extraction disk. 


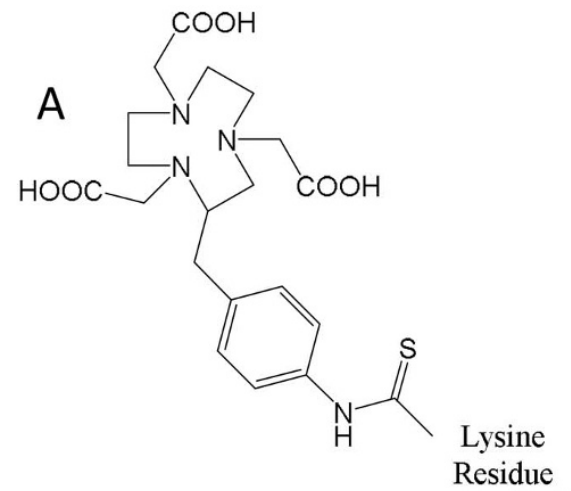

on Antibody

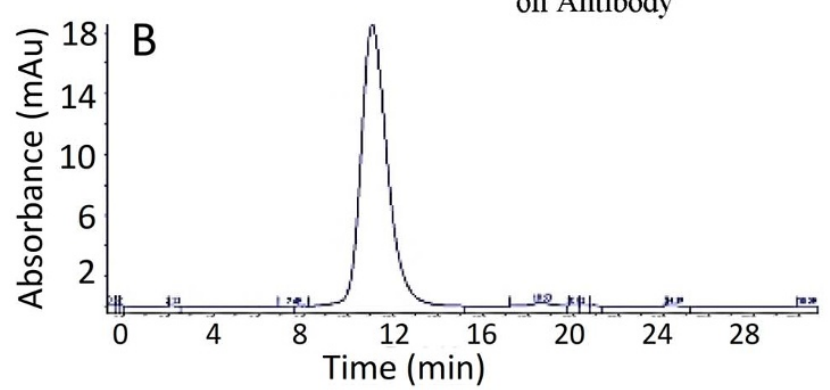

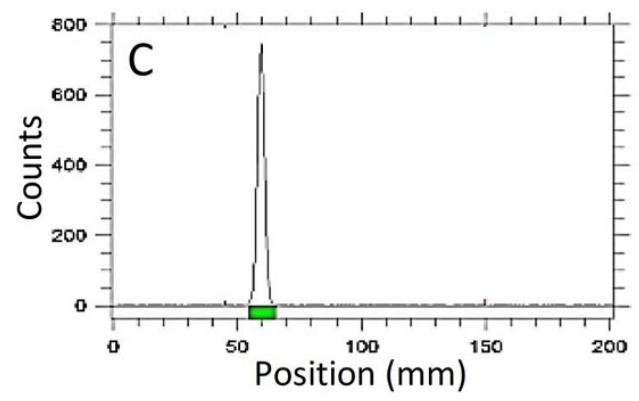

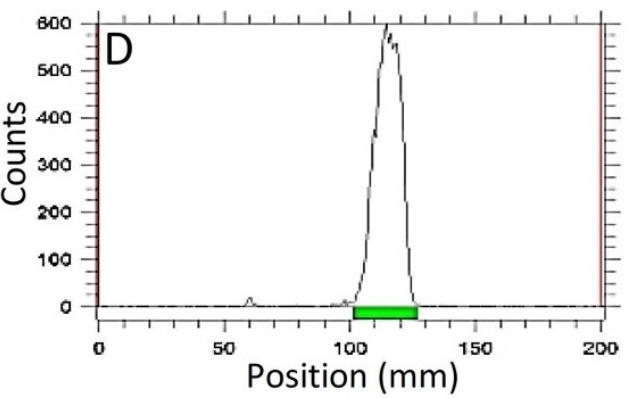

Figure $3 \mid$ (A) Structure of the NOTA-Bz-NCS conjugated to lysine residues on Trastuzumab. (B) Fast Protein Liquid Chromatography of NOTA-BzNCS-Trastuzumab indicating an intact conjugated antibody. (C) Radio instant thin layer chromatography of ${ }^{67} \mathrm{Cu}-\mathrm{NOTA}-\mathrm{Bz}-\mathrm{NCS}-\mathrm{Trastuzumab}$ challenged with EDTA. The sharp peak at $60 \mathrm{~mm}$ and the absence of a later peak signifies a fully labeled antibody. (D) Similar to (C) where a broad peak between 100-130 mm signifies ${ }^{67} \mathrm{Cu}-\mathrm{EDTA}$ and serves as a negative control.

Germanium Separation Validation. Several concentrations of aqueous germanium ranging from $0.04-0.5 \mathrm{ppm}$ in $1.25 \mathrm{M}$ ammonium acetate were passed through the extraction disk using the method described above. The chelation disk was analyzed using particle-induced $\mathrm{x}$-ray emission (PIXE) by irradiating the chelation disk with 3.4 MeV protons for five minutes at beam intensities between $2.25-2.80 \mathrm{nA}$. A Si(Li) detector was used to measure the resulting $\mathrm{x}$-rays. The characteristic $\mathrm{K}_{\alpha} \mathrm{X}$-rays for germanium were analyzed to determine the amount of germanium bound to the chelation disk.

${ }^{68} \mathrm{Ga}$ and ${ }^{64} \mathrm{Cu}$ Separation Validation. $200 \mu \mathrm{Ci}$ of ${ }^{68} \mathrm{Ga}$ obtained from a ${ }^{68} \mathrm{Ge} /{ }^{68} \mathrm{Ga}$ generator and $200 \mu \mathrm{Ci}$ of ${ }^{64} \mathrm{Cu}$ produced at Washington University in St. Louis were added to $100 \mathrm{~mL}$ of $1.25 \mathrm{M}$ ammonium acetate and passed through the extraction disk using the method given above. The extraction disk was surveyed by HPGe for ${ }^{68} \mathrm{Ga}$ and ${ }^{64} \mathrm{Cu}$ using the characteristic gamma rays, $1077.3 \mathrm{keV}(3.22 \%)$ for ${ }^{68} \mathrm{Ga}$ and $1345.8 \mathrm{keV}(0.475 \%)$ for ${ }^{64} \mathrm{Cu}$. The extraction disk was returned to the filter holder and $10 \mathrm{~mL}$ of $6 \mathrm{M}$ hydrochloric acid (trace metals grade) was added to remove ${ }^{64} \mathrm{Cu}$ from the extraction disk. Both the extraction disk and the filtrate were analyzed by HPGe to measure amounts of ${ }^{68} \mathrm{Ga}$ and ${ }^{64} \mathrm{Cu}$ present in each.

Copper, Nickel, and Zinc Separation Validation. Aqueous solutions containing $100 \mu \mathrm{g}$ of copper, nickel and zinc (1000 mg/L AAS Standards, Sigma Aldrich, USA) were added to $100 \mathrm{~mL} 1.25 \mathrm{M}$ ammonium acetate solution at $\mathrm{pH} 5$ and passed through the chelation disk as described above. $10 \mathrm{~mL}$ of $6 \mathrm{M}$ hydrochloric acid (trace metals grade) was then added to remove the nickel, copper, and zinc that were bound to the chelation disk. This solution was then passed through an anion-exchange column using $2.5 \mathrm{~g}$ AG1-8X resin (Bio-Rad, USA) and washed with an additional $10 \mathrm{~mL}$ of $6 \mathrm{M} \mathrm{HCl}$ to remove the nickel followed by $10 \mathrm{~mL}$ of $0.5 \mathrm{M} \mathrm{HCl}$ to remove the copper. Each $10 \mathrm{~mL}$ fraction was brought to dryness by evaporation through overnight heating at $80^{\circ} \mathrm{C}$ and reconstituted in $1 \mathrm{~mL}$ Ultratrace water (Sigma Aldrich, USA) and analyzed by an HPLC trace metal ion chromatography method ${ }^{24}$.

${ }^{67} \mathrm{Cu}$ Separation. First, each $100 \mathrm{~mL}$ sample was turned into a $1.25 \mathrm{M}$ solution of $\mathrm{NH}_{4} \mathrm{OAc}$ by adding $9.6 \mathrm{~g}$ trace metals grade ammonium acetate and $\mathrm{pH}$ adjusted to 5 by adding trace metals grade acetic acid. The $\sim 100 \mathrm{~mL}$ solution was then passed through the chelation disk as described above. The filter holder was transferred to a clean vacuum flask and $10 \mathrm{~mL}$ of $6 \mathrm{M}$ trace metals grade hydrochloric acid was passed through to remove the ${ }^{67} \mathrm{Cu}$ along with the nickel and zinc contaminants. The $6 \mathrm{M} \mathrm{HCl}$ elution was then transferred to an anion-exchange column with AG1-X8 resin, the $10 \mathrm{~mL}$ eluate was collected and then an additional $10 \mathrm{~mL}$ of $6 \mathrm{M}$ hydrochloric acid was passed through the column and collected. Finally $10 \mathrm{~mL} 0.5 \mathrm{M}$ hydrochloric acid was added to the resin and $1 \mathrm{~mL}$ fractions of the eluate were collected. All eluates were analyzed for radiochemical purity by observing the characteristic gamma rays in an HPGe detector.

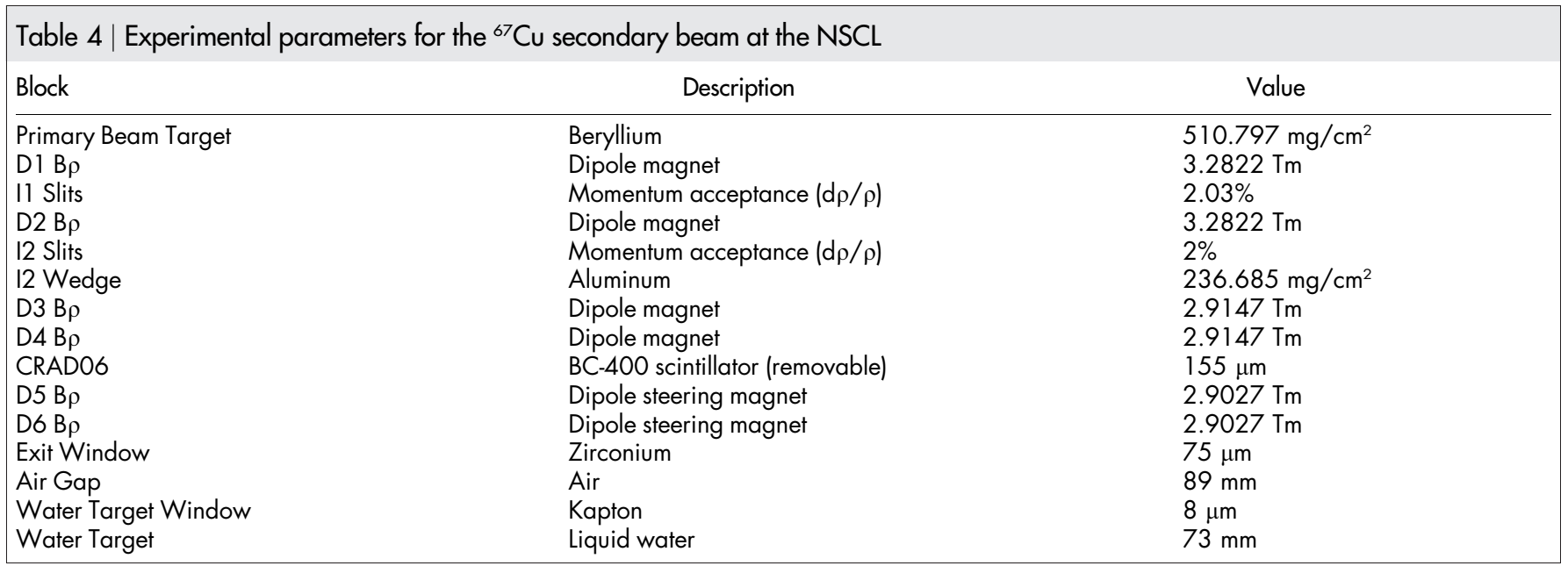


${ }^{67} \mathrm{Cu}-\mathrm{NOTA}$-Trastuzumab Labelling. A $10 \mathrm{mg} / \mathrm{mL}$ stock of NOTA-NCS was made by dissolving $3.66 \mathrm{mg}$ NOTA-NCS (Macrocyclics, USA) in 366 uL Dimethyl sulfoxide. $50 \mathrm{uL}$ of $21 \mathrm{ug} / \mathrm{uL}$ Trastuzumab (Genentech, USA) was added to $4 \mathrm{uL}$ NOTA-NCS stock solution and 96 uL $0.1 \mathrm{M}$ sodium carbonate $\mathrm{pH} 9.0$ and incubated for $1 \mathrm{hr}$ at $37 \mathrm{C}$ on a shaking incubator. A Zeba spin desalting column $(40 \mathrm{~K}, 0.5 \mathrm{~mL})$ was used to buffer exchange into $0.1 \mathrm{M}$ ammonium acetate buffer at $\mathrm{pH} 5.5$ Concentration of the NOTA-Bz-NCS-Trastuzumab was measured using the bicinchoninic acid (BCA) assay.

The two $1 \mathrm{~mL} 0.5 \mathrm{M}$ hydrochloric acid samples with the largest amounts of ${ }^{67} \mathrm{Cu}$ were brought to dryness and reconstituted using $50 \mathrm{uL}$ of $0.1 \mathrm{M}$ ammonium acetate at $\mathrm{pH}$ 5.5. $5 \mathrm{uL}$ was transferred to a new tube and $5 \mathrm{uL} 50 \mathrm{mmol}$ EDTA was added. The remaining $45 \mathrm{uL}$ was added to a microfuge tube along with $2 \mathrm{uL}$ NOTA-BzNCS-Trastuzumab and brought to $50 \mathrm{uL}$ by adding $0.1 \mathrm{M}$ ammonium acetate at pH5.5. Tubes were placed in a shaking incubator at $37^{\circ} \mathrm{C}$ for twenty minutes. This method was adapted from one previously reported by Ferreira et al. ${ }^{25}$ The solution containing ${ }^{67} \mathrm{Cu}$-NOTA-Bz-NCS-Trastuzumab was then challenged with $1 \mu \mathrm{L}$ $50 \mathrm{mmol}$ EDTA. $1 \mathrm{uL}$ from each tube was spotted on ITLC paper (Agilent,) at $2 \mathrm{~cm}$ from the bottom of the paper and placed in $1 \mathrm{~cm}$ running buffer $(1: 110 \%$ ammonium acetate and methanol) and ran until the eluent was $5 \mathrm{~cm}$ past the starting point $(7 \mathrm{~cm}$ total). The paper was then analyzed by radio TLC scanner.

${ }^{7}$ Be Cross Section Analysis. After allowing the short-lived isotopes to decay, the $100 \mathrm{~mL}$ eluent from the chelation disk was analyzed for presence of ${ }^{7} \mathrm{Be}$ using $\mathrm{HPGe}$ analysis of the $477 \mathrm{keV}$ gamma ray (10.44\%) present in spectra collected for 12 and 24 hours. The counts were decay corrected back to the end of each collection run.

1. Brzezinski, M. A. \& Phillips, D. R. Evaluation of Si-32 as a tracer for measuring silica production rates in marine waters. Limnology and oceanography $\mathbf{4 2}$, 856-865 (1997).

2. Brzezinski, M. A., Phillips, D. R., Chavez, F. P., Friederich, G. E. \& Dugdale, R. C. Silica production in the Monterey, California, upwelling system. Limnology and oceanography 42, 1694-1705 (1997).

3. Leising, M. Endangered and Extinct Radioactivity. Meteoritics 28, 385 (1993).

4. De Cremer, K. et al. Behaviour of vanadate and vanadium-transferrin complex on different anion-exchange columns. Application to in vivo V-48-labelled rat serum. J Chromatogr B 775, 143-152, Doi 10.1016/S1570-0232(02)00278-7 (2002).

5. DeNardo, G. L. et al. Efficacy and toxicity of Cu-67-2IT-BAT-Lymradioimmunoconjugate in mice implanted with human Burkitt's lymphoma (Raji). Clinical Cancer Research 3, 71-79 (1997).

6. O'Donnell, R. T. et al. A clinical trial of radioimmunotherapy with Cu-67-2ITBAT-Lym-1 for non-Hodgkin's lymphoma. Journal of Nuclear Medicine 40, 2014-2020 (1999).

7. Abia, C. et al. The (KR)-K- 85 s-process branching and the mass of carbon stars. Astrophys J 559, 1117-1134, doi: Doi 10.1086/322383 (2001).

8. Pen, A. et al. Design and construction of a water target system for harvesting radioisotopes at the National Superconducting Cyclotron Laboratory. Nucl Instrum Meth A 747, 62-68, doi: DOI 10.1016/j.nima.2014.02.010 (2014).

9. Hausmann, M. et al. Design of the Advanced Rare Isotope Separator ARIS at FRIB. Nucl Instrum Meth B 317, 349-353, doi: DOI 10.1016/j.nimb.2013.06.042 (2013).

10. Schwarzbach, R., Zimmermann, K., Blauenstein, P., Smith, A. \& Schubiger, P. A. Development of a Simple and Selective Separation of Cu-67 from Irradiated Zinc for Use in Antibody Labeling - a Comparison of Methods. Applied Radiation and Isotopes 46, 329-336, doi: Doi 10.1016/0969-8043(95)00010-B (1995).

11. Zimmermann, K. et al. Targeting of renal carcinoma with (CU)-C-67/64-labeled anti-L1-CAM antibody chCE7: selection of copper ligands and PET imaging. Nuclear Medicine and Biology 30, 417-427, doi: Doi 10.1016/S09698051(03)00019-2 (2003).

12. Smith, N. A., Bowers, D. L. \& Ehst, D. A. The production, separation, and use of $\mathrm{Cu}-67$ for radioimmunotherapy: A review. Applied Radiation and Isotopes $\mathbf{7 0}$ 2377-2383, doi: DOI 10.1016/j.apradiso.2012.07.009 (2012).

13. Connett, J. M. et al. Radioimmunotherapy with a $\mathrm{Cu}-64$-labeled monoclonal antibody: A comparison with Cu-67. P Natl Acad Sci USA 93, 6814-6818, doi: DOI 10.1073/pnas.93.13.6814 (1996).

14. Novak-Hofer, I. \& Schubiger, P. A. Copper-67 as a therapeutic nuclide for radioimmunotherapy. Eur J Nucl Med Mol I 29, 821-830, doi: DOI 10.1007/ s00259-001-0724-y (2002).
15. Dasgupta, A. K., Mausner, L. F. \& Srivastava, S. C. A New Separation Procedure for Cu-67 from Proton Irradiated Zn. Applied Radiation and Isotopes 42, 371-376 (1991).

16. Mausner, L. F., Kolsky, K. L., Joshi, V. \& Srivastava, S. C. Radionuclide development at BNL for nuclear medicine therapy. Applied Radiation and Isotopes 49, 285-294, doi: Doi 10.1016/S0969-8043(97)00040-7 (1998).

17. Norenberg, J. et al. Workshop on the Nation's Needs for Isotopes: Present and Future. Published by the US DOE Office of Science, Rockville, Maryland (2008) (Date of access: 03/18/2013).

18. Jamriska, D. J. et al. Activation Rates and Chemical Recovery of Cu-67 Produced with Low-Energy Proton Irradiation of Enriched Zn-70 Targets. J Radioan Nucl Ch Ar 195, 263-270, doi: Doi 10.1007/Bf02035965 (1995).

19. Kastleiner, S., Coenen, H. H. \& Qaim, S. M. Possibility of production of $\mathrm{Cu}-67$ at a small-sized cyclotron via the (p,alpha)-reaction on enriched $\mathrm{Zn}$-70. Radiochim Acta 84, 107-110 (1999).

20. Hilgers, K., Stoll, T., Skakun, Y., Coenen, H. H. \& Qaim, S. M. Cross-section measurements of the nuclear reactions Zn-nat(d,x)Cu-64, Zn-66(d,alpha)Cu-64 and $\mathrm{Zn}-68(\mathrm{p}$,alpha $\mathrm{n}) \mathrm{Cu}-64$ for production of $\mathrm{Cu}-64$ and technical developments for small-scale production of $\mathrm{Cu}-67$ via the $\mathrm{Zn}-70$ (p,alpha)Cu-64 process. Applied Radiation and Isotopes 59, 343-351, doi: Doi 10.1016/S0969-8043(03)00199-4 (2003).

21. Ronningen, R. Isotope Inventories in Cooling Loop. 2nd Workshop on Isotope Harvesting at FRIB http://meetings.nscl.msu.edu/IsotopeWorkshop2012/home. html (2012) (Date of access: 07/25/2012).

22. Morrissey, D. J., Sherrill, B. M., Steiner, M., Stolz, A. \& Wiedenhoever, I. Commissioning the A1900 projectile fragment separator. Nucl Instrum Meth B 204, 90-96, doi: Doi 10.1016/S0168-583x(02)01895-5 (2003).

23. Kume, M. et al. A semi-automated system for the routine production of copper64. Applied radiation and isotopes 70, 1803-1806, doi: 10.1016/ j.apradiso.2012.03.009 (2012)

24. Mastren, T. et al. Specific activity measurement of $64 \mathrm{Cu}$ : a comparison of methods. Applied radiation and isotopes 90C, 117-121, doi: 10.1016/ j.apradiso.2014.03.016 (2014).

25. Ferreira, C. L. et al. Comparison of bifunctional chelates for Cu-64 antibody imaging. Eur J Nucl Med Mol I 37, 2117-2126, doi: DOI 10.1007/s00259-0101506-1 (2010).

\section{Acknowledgments}

We would like to acknowledge the help and support from the A1900 staff and NSCL Operations group for providing the ${ }^{67} \mathrm{Cu}$ secondary beam, the MSU Environmental Health and Safety group for their help and oversight, Dave Daugherty at Hope College for help with the end station, and Jon Elson, Bernadette Marquez, and Tom Voller at Washington University in St. Louis for help with the radiation detector system, antibody labeling, and shipping procedures respectively. This work was supported by the DOE Office of Science Grant DE-SC0007352 and in part by the NSF under cooperative agreement PHY-11-02511. TM and SEL are also supported by the Department of Energy National Nuclear Security Administration under Award Number DE-NA0000979.

\section{Author contributions}

The experiments were carried out by T.M., A.P., G.F.P., N.W., S.L., S.E., D.J.M. and S.E.L. Data Analysis was carried out by T.M., A.P., G.F.P., L.G.S., D.J.M. and S.E.L. T.M. wrote the main manuscript text and prepared figures 1-3. All authors reviewed the manuscript.

\section{Additional information}

Competing financial interests: The authors declare no competing financial interests.

How to cite this article: Mastren, T. et al. Feasibility of Isotope Harvesting at a Projectile Fragmentation Facility: ${ }^{67} \mathrm{Cu}$. Sci. Rep. 4, 6706; DOI:10.1038/srep06706 (2014).

This work is licensed under a Creative Commons Attribution-NonCommercialNoDerivs 4.0 International License. The images or other third party material in this article are included in the article's Creative Commons license, unless indicated otherwise in the credit line; if the material is not included under the Creative Commons license, users will need to obtain permission from the license holder in order to reproduce the material. To view a copy of this license, visit http:// creativecommons.org/licenses/by-nc-nd/4.0/ 